\title{
Trends, risk factors and outcomes of healthcare- associated infections within the Italian network SPIN-UTI
}

\author{
A. Agodi ${ }^{a, *}$, F. Auxilia ${ }^{b}$, M. Barchitta ${ }^{a}$, S. Brusaferro ${ }^{c}$, D. D'Alessandro ${ }^{\text {, }}$, \\ O.C. Grillo ${ }^{\text {e }}$, M.T. Montagna ${ }^{f}$, C. Pasquarella ${ }^{g}$, E. Righi ${ }^{\text {h }}$, S. Tardivo ${ }^{i}$, \\ V. Torregrossa ${ }^{\mathrm{j}}$, I. Murak ${ }^{\mathrm{k}}$, GISIO-SITI' \\ a Department GF Ingrassia, University of Catania, Via S. Sofia 87, 95123 Catania, Italy \\ ${ }^{b}$ Department of Biomedical Sciences for Health, University of Milan, Via Carlo Pascal 36, 20133 Milan, Italy \\ ${ }^{\mathrm{c}}$ Department of Medical and Biological Sciences, University of Udine, Via Colugna 40, 33100 Udine, Italy \\ 'Department of Civil Building and Environmental Engineering, 'Sapienza' University, Rome, Via Eudossiana 18, 00186 Rome, Italy \\ e Department of Preventive Medicine and Public Health, University of Messina, Policlinico Universitario Torre Biologica, \\ Via C. Valeria Gazzi, 98100 Messina, Italy \\ 'Department of Biomedical Sciences and Human Oncology, Hygiene Section, University of Bari 'Aldo Moro', \\ Policlinico - Piazza G. Cesare 11, 70124 Bari, Italy \\ ${ }^{\mathrm{g}}$ Department of Biomedical Biotechnological and Translational Sciences, University of Parma, Via Volturno 39, \\ 43125 Parma, Italy \\ ${ }^{\mathrm{h}}$ Department of Diagnostic Medicine, Clinic and Public Health, University of Modena and Reggio Emilia, Via G. Campi 287, \\ 41125 Modena, Italy \\ 'Department of Public Health and Community Medicine, University of Verona, Policlinico G.B. Rossi - P.le L.A. Scuro 10, \\ 37134 Verona, Italy \\ ${ }^{\mathrm{j}}$ Department of Sciences for Health Promotion, University of Palermo, Via del Vespro 133, 90127 Palermo, Italy \\ ${ }^{k}$ Department of Biomedical Sciences, University of Sassari, viale San Pietro 43/B, 07100 Sassari, Italy \\ ' GISIO-SItI, Italian Study Group of Hospital Hygiene-Italian Society of Hygiene, Preventive Medicine and Public Health, Italy
}

\section{A R T I C L E I N F O}

\section{Article history:}

Received 31 October 2012

Accepted 10 February 2013

Available online 30 March 2013

\section{Keywords:}

Acinetobacter baumannii

Intubation

Mortality

\section{$S \cup M M A R Y$}

Background: Implementing infection control measures in light of healthcare-associated infection (HAI) surveillance data can prevent HAls. Surveillance has been associated with a reduction of $\mathrm{HAl}$ in intensive care unit (ICU) patients, though the reasons for this improvement remain unclear.

Aim: To evaluate changes in healthcare-associated infection (HAI) rates during three surveys of the Italian Nosocomial Infections Surveillance in Intensive Care Units (ICUs) network (SPIN-UTI) six-year project and to explore sources of variation of indicators of HAI in the 65 participating ICUs.

Methods: The SPIN-UTI network adopted the European protocols for patient-based HAI surveillance. Cumulative incidence, incidence density, infection rates adjusted for device-

\footnotetext{
* Corresponding author. Address: Department GF Ingrassia, University of Catania, Via S. Sofia n. 87, 95123 Catania, Italy. Tel./fax: + 390953782183 .

E-mail address: agodia@unict.it (A. Agodi).
} 
Prevention

Surveillance days, and device utilization ratios were calculated for each survey and compared. To identify risk factors multiple logistic regression analyses were performed. Crude excess mortality was computed as the difference between the crude overall case-fatality rate of patients with and without HAI.

Findings: The risk of ICU-acquired infections increased in the third survey compared with previous (relative risk: 1.215; 95\% confidence interval: 1.059-1.394). Among risk factors, the number of hospitalized patients requiring ICU admission and the Simplified Acute Physiology Score II increased from $73.7 \%$ to $78.1 \%$ and from $37.9 \%$ to $40.8 \%$ respectively. Although mortality rates remained unchanged, HAls trebled the risk of death. Acinetobacter baumannii was the most frequently reported micro-organism in the third survey (16.9\%), whereas in the previous surveys it ranked third (7.6\%) and second (14.3\%).

Conclusions: The study highlighted the increased risk of HAI, at least partially explained by the greater severity and number of hospitalized patients requiring ICU admission. Furthermore, the management of intubation procedures and of ventilated patients was identified as a potential target for infection control interventions to decrease the growing risk of HAI in ICUs.

(c) 2013 The Healthcare Infection Society. Published by Elsevier Ltd. All rights reserved.

\section{Introduction}

Reporting and analysing healthcare-associated infection (HAl) surveillance data, with subsequent changes to infection control measures, can prevent HAls. ${ }^{1-4}$ Conducting surveillance has been associated with a reduction of $\mathrm{HAl}$ rates in intensive care unit (ICU) patients, although the particular reasons for this decrease are still difficult to determine. ${ }^{5-7}$

The Italian Nosocomial Infections Surveillance in ICUs network, Sorveglianza Prospettica delle Infezioni Nosocomiali nelle Unità di Terapia Intensiva (SPIN-UTI), was established in Italy in 2005 by the Italian Study Group of Hospital Hygiene (GISIO) of the Italian Society of Hygiene, Preventive Medicine and Public Health (SItI). ${ }^{8}$ The SPIN-UTI project has adopted a protocol based on that from the Hospitals in Europe Link for Infection Control through Surveillance (HELICS) network, subsequently updated in accordance with the European Centre for Disease Control and Prevention (ECDC) HAlICU protocol. ${ }^{9,10}$ Italy - first among the European Countries to follow the HELICS-ICU protocol - had conducted a validation study on the SPIN-UTI surveillance data in order to determine the sensitivity, specificity, and positive and negative predictive values of HAI data. ${ }^{11}$ The SPIN-UTI network has been acknowledged by the Italian CCM (Centro per il Controllo delle Malattie, Ministry of Health) and has been included in the HELICS-ICU network and as a partner of the IPSE (Improving Patient Safety in Europe) project, of the BURDEN (Burden of Disease and Resistance in European Nations) project, and of the IMPLEMENT (Implementing Strategic Bundles for Infection Prevention and Management) project.

Here, we report surveillance data from the three surveys of the SPIN-UTI six-year project (2006-2011), in order to evaluate any change in infection rates during the study period and to explore sources of variation of indicators of $\mathrm{HAl}$ in the 65 participating ICUs.

\section{Methods}

\section{Surveillance methodology}

Each survey of the SPIN-UTI project consisted of six months of patient-based surveillance conducted between the last quarter of one year and the first quarter of the following year.
The first and second surveys, respectively conducted from November 2006 to April 2007, and from October 2008 to March 2009, adopted methods and definitions of the HELICS-ICU protocol. ${ }^{8,9}$ In the third survey, carried out from October 2010 to March 2011, the protocol was updated following the ECDC HAlICU protocol, implemented in 2010 by the ECDC's TESSy, The European Surveillance System for communicable diseases. ${ }^{10}$

Hospital participation was voluntary and results were handled confidentially. Codes for hospitals and ICUs and patient identifiers were anonymous at the level of the surveillance network. Surveillance was conducted by infection control practitioners, intensive care specialists and other personnel trained in the surveillance methodology and in ECDC definitions. A web-based data collection procedure by means of four electronic data forms, designed using SPSS Data Entry Enterprise Server (SPSS Inc.), was used. At the end of each survey, participating ICUs received a report on surveillance data as feedback, in order to encourage infection control activities on the basis of benchmark indicators.

The selected HAl indicators; cumulative incidence, incidence density, infection rates adjusted for device-days and device utilization ratios, were calculated for each survey as previously reported and compared. ${ }^{8}$ The 'relevant devices' were: intubation, central vascular catheters, and urinary catheters, respectively.

Crude excess mortality was computed as the difference between the crude overall case-fatality rate of patients with HAI and the crude case-fatality rate of patients without HAl in the ICU during the same survey period. Similarly, the crude excess mortalities for patients who developed pneumonia, for patients who developed a bloodstream infection (BSI) and for patients with Acinetobacter baumannii infection were calculated.

\section{Statistical analyses}

Statistical analyses were performed using the SPSS 14.0 statistical package. Patients' characteristics were compared using the $\chi^{2}$-test for categorical variables and Student's $t$-test for continuous variables; $P \leq 0.05$ was considered significant. To compare the infection rates and cumulative incidences between the three surveys, relative risk (RR) values with $95 \%$ confidence intervals (Cls) were determined. Device utilization ratios were compared using the $\chi^{2}$-test, and $P \leq 0.05$ was considered significant. 
In order to assess survey-specific $\mathrm{HAl}$-associated risk factors, a case-control study was designed for each edition of the project. Case patients were those with HAl; control patients were those without HAI. For quantitative variables the median value was chosen as the cut-off point. The association of all variables with the occurrence of HAl was assessed using the $\chi^{2}$ test. In order to take into account the influence of risk factors for HAls, for each survey of the project, significant variables $(P \leq 0.05)$ were included in a multiple logistic regression model for multivariate analysis, with stepwise variable selection.

\section{Results}

\section{Surveillance indicators}

A total of 65 ICUs participated in at least one edition of the SPIN-UTI project continuously for at least six months, and contributed data to the surveillance database. The number of ICUs participating in each survey were: 49, 28 and 27, respectively. A total of 14 ICUs (21.5\%) participated in all three surveys. Characteristics of the 7694 patients admitted to the ICUs for more than two days during the three surveys are reported in Table I. A significant increase in the mean age and Simplified Acute Physiology Score (SAPS) II score of patients, a decrease in the mean length of ICU stay and an increase in the proportion of patients admitted from the hospital rather than from community were observed in the third survey of the project compared with the previous surveys.

In all three surveys the most frequently detected infection type was pneumonia. The risk of ICU-acquired infections, estimated by computing the cumulative incidence and the incidence density, significantly increased in the third survey compared with the previous survey (Table II).

\section{Time trends for HAl-associated micro-organisms}

Relative frequencies of the most commonly isolated microorganisms in ICU-acquired infections are reported in Figure 1.
A. baumannii was the most frequently reported microorganism in the third survey $(16.9 \%)$, whereas in the two previous surveys it ranked third (7.6\%) and second $(14.3 \%)$, respectively $(P<0.05)$. Pseudomonas aeruginosa was the most frequently reported micro-organism in the first $(19.4 \%)$ and in the second surveys $(16.9 \%)$ whereas in the third survey it ranked second $(14.4 \%)(P<0.05)$. In the third survey a significant increase in the frequency of isolation was reported for Escherichia coli compared with previous surveys $(10.6 \%$ versus $6.4 \%$ and $5.9 \%$ ). In the last two surveys a significant increase in the frequency of isolation was reported for Klebsiella pneumoniae (8.6\% and $9.3 \%$ versus $5.3 \%)$. For Staphylococcus epidermidis a significant decrease was observed in the second survey compared with the first $(3.8 \%$ versus $6.9 \%)$ and then a significant increase in the third survey compared with the second (6.4\% versus 3.8\%). Finally, for Staphylococcus aureus a significant decrease in the frequency of isolation was reported in the third and in the second surveys compared with the first (5.4\% and $5.5 \%$ versus $9.6 \%$ ).

Relative frequencies and site-specific pathogen distributions of the most frequently isolated micro-organisms in ICUacquired infections are reported in Table III.

Risk trends estimated by computing the cumulative incidence, the incidence density and the device-associated infection rates for $A$. baumannii and $E$. coli-associated infection did not differ significantly from those computed for infections associated with other micro-organisms (data not shown).

\section{Risk factor analysis}

To take into account the influence of risk factors for HAls, multiple logistic regression analyses with stepwise variable selection were performed for each survey of the project.

Among risk factors identified in each survey, and taking into account the type of ICU and the Acute Physiology And Chronic Health Evaluation (APACHE) II score, the proportion of patients being admitted to ICUs from other hospital wards and the SAPS

Table I

Comparison of main characteristics of patients included in SPIN-UTI surveys

\begin{tabular}{|c|c|c|c|c|c|c|}
\hline \multirow[t]{2}{*}{ Characteristics } & \multicolumn{3}{|c|}{ SPIN-UTI } & \multicolumn{3}{|c|}{$P$-value, comparison between: } \\
\hline & $2006-2007$ & $2008-2009$ & $2010-2011$ & $\begin{array}{l}\text { 1st and } 2 \text { nd } \\
\text { surveys }\end{array}$ & $\begin{array}{l}\text { 1st and 3rd } \\
\text { surveys }\end{array}$ & $\begin{array}{c}\text { 2nd and } 3 r d \\
\text { surveys }\end{array}$ \\
\hline No. of ICUs (no. of hospitals) & $49(32)$ & $28(22)$ & $27(22)$ & - & - & - \\
\hline No. of patients & 3053 & 2163 & 2478 & - & - & - \\
\hline Mean age (years) & 63.7 & 66.0 & 67.1 & 0.00 & 0.00 & 0.01 \\
\hline Male $(\%)$ & 61.6 & 62.8 & 59.7 & 0.41 & 0.14 & 0.03 \\
\hline Mean length of ICU stay (days) & 11.6 & 10.5 & 10.0 & 0.00 & 0.00 & 0.18 \\
\hline Mortality (\%) & 17.7 & 18.3 & 18.2 & 0.61 & 0.61 & 0.98 \\
\hline SAPS II score (mean) & 38.1 & 37.9 & 40.8 & 0.82 & 0.00 & 0.00 \\
\hline $\begin{array}{l}\text { Origin of the patient from } \\
\text { hospital (\%) }\end{array}$ & 67.1 & 73.7 & 78.1 & 0.00 & 0.00 & 0.00 \\
\hline Trauma patients (\%) & 4.2 & 4.0 & 3.9 & 0.78 & 0.61 & 0.83 \\
\hline $\begin{array}{l}\text { Patients needing acute } \\
\text { coronary care }(\%)\end{array}$ & 28.9 & 11.8 & 13.9 & 0.00 & 0.00 & 0.00 \\
\hline Impaired immunity (\%) & 3.7 & 3.8 & 3.5 & 0.87 & 0.65 & 0.56 \\
\hline $\begin{array}{l}\text { Antibiotic treatment in } 48 \mathrm{~h} \\
\text { before or after ICU admission (\%) }\end{array}$ & 59.9 & 64.6 & 62.8 & 0.00 & 0.00 & 0.21 \\
\hline
\end{tabular}

SPIN-UTI, Italian Nosocomial Infections Surveillance in ICUs network; ICU, Intensive Care Unit; SAPS, Simplified Acute Physiology Score. 
Table II

Comparison of infection indicators in the three surveys of the SPIN-UTI project

\begin{tabular}{|c|c|c|c|c|c|c|}
\hline \multirow[t]{2}{*}{ Indicators } & \multicolumn{3}{|c|}{ SPIN-UTI } & \multicolumn{3}{|c|}{ RR $(95 \% \mathrm{Cl})$ or $P$-value, comparison between: } \\
\hline & $2006-2007$ & $2008-2009$ & $2010-2011$ & $\begin{array}{l}\text { 2nd and } 1 \text { st } \\
\text { surveys }\end{array}$ & $\begin{array}{l}\text { 3rd and } 1 \text { st } \\
\text { surveys }\end{array}$ & $\begin{array}{l}3 \text { rd and } 2 \text { nd } \\
\text { surveys }\end{array}$ \\
\hline Pneumonia (\%) & 53.6 & 47.3 & 51.7 & & & \\
\hline Bloodstream infection (\%) & 23.4 & 22.5 & 25.7 & & & \\
\hline Urinary tract infection $(\%)$ & 16.7 & 22.3 & 15.6 & & & \\
\hline Catheter-related infection (\%) & 6.3 & 7.9 & 7.1 & & & \\
\hline $\begin{array}{l}\text { Cumulative incidence of infections } \\
\text { (per } 100 \text { patients) }\end{array}$ & 19.8 & 19.9 & 22.3 & $1.01(0.89-1.14)$ & $1.12(1.00-1.26)$ & $1.13(0.99-1.28)$ \\
\hline $\begin{array}{l}\text { Cumulative incidence of infected } \\
\text { patients (per } 100 \text { patients) }\end{array}$ & 11.7 & 11.9 & 14.2 & $1.02(0.88-1.19)$ & $1.2^{\mathrm{a}}(1.06-1.39)$ & $1.19^{a}(1.03-1.39)$ \\
\hline $\begin{array}{l}\text { Incidence density } \\
\quad \text { (per } 1000 \text { patient-days) }\end{array}$ & 17.1 & 19.0 & 22.4 & $1.11(0.98-1.26)$ & $1.31^{\mathrm{a}}(1.17-1.47)$ & $1.18^{\mathrm{a}}(1.04-1.34)$ \\
\hline $\begin{array}{l}\text { Percentage of patients } \\
\text { who experienced } \\
\text { pneumonia }\end{array}$ & $8.4 \%$ & $7.5 \%$ & $9.9 \%$ & & & \\
\hline $\begin{array}{l}\text { Intubator-associated pneumonia } \\
\text { rate (per } 1000 \text { intubator-days) }\end{array}$ & 15.6 & 12.9 & 17.3 & $0.83^{\mathrm{a}}(0.69-0.99)$ & $1.11(0.94-1.31)$ & $1.34^{\mathrm{a}}(1.11-1.62)$ \\
\hline $\begin{array}{l}\text { Percentage of patients who } \\
\text { experienced a BSI }\end{array}$ & $3.9 \%$ & $3.5 \%$ & $5.0 \%$ & & & \\
\hline BSIs rate (per 1000 patient-days) & 4.0 & 4.3 & 5.7 & $1.08(0.83-1.39)$ & $1.43^{\mathrm{a}}(1.13-1.80)$ & $1.33^{\mathrm{a}}(1.02-1.72)$ \\
\hline $\begin{array}{l}\text { UC-associated UTIs } \\
\text { (per } 1000 \text { UC-days) }\end{array}$ & 4.2 & 4.5 & 3.7 & $1.07(0.81-1.42)$ & $0.88(0.66-1.18)$ & $0.82(0.61-1.10)$ \\
\hline $\begin{array}{l}\text { CVC-associated infections rate } \\
\text { (per } 1000 \text { CVC-days) }\end{array}$ & 1.6 & 1.7 & 1.8 & $1.06(0.66-1.72)$ & $1.13(0.71-1.78)$ & $1.06(0.66-1.69)$ \\
\hline Intubator utilization ratio & 0.55 & 0.64 & 0.62 & $P<0.00$ & $P<0.00$ & $P<0.00$ \\
\hline CVC utilization ratio & 0.58 & 0.82 & 0.85 & $P<0.00$ & $P<0.00$ & $P<0.00$ \\
\hline UC utilization ratio & 0.58 & 0.82 & 0.90 & $P<0.00$ & $P<0.00$ & $P<0.00$ \\
\hline
\end{tabular}

SPIN-UTI, Italian Nosocomial Infections Surveillance in ICUs network; RR, relative risk; CI, confidence interval; BSI, bloodstream infection; UTI, urinary tract infection; CRI, catheter-related infection; UC, urinary catheter; CVC, central venous catheter.

Device-associated infection rates: number of device-related infections per 1000 device-days.

Utilization ratios: number of device days/number of patient-days.

a Statistically significant $(P \leq 0.05)$.

II both increased significantly in the third survey, from $73.7 \%$ to $78.1 \%$ and from 37.9 to 40.8 (mean values) respectively.

\section{Mortality analysis}

During the three surveys, mortality rates remained unchanged (Table I), whereas the risk of death increased for infected patients from RR $=2.25(95 \% \mathrm{Cl}: 1.90-2.66)$ in the first survey, to RR $=2.96(95 \% \mathrm{Cl}: 2.48-3.54)$ in the second survey, and to $\mathrm{RR}=3.19(95 \% \mathrm{Cl}: 2.71-3.74)$ in the third. The crude excess mortality for patients with HAI increased from $19.3 \%$ in the first survey to $29.2 \%$ in the second and $30.7 \%$ in the third. The crude excess mortality for patients with pneumonia increased from $19.1 \%$ in the first survey to $31.4 \%$ in the second and to $32.3 \%$ in the third. The crude excess mortality for patients with BSI increased from $17.1 \%$ in the first survey to $32.9 \%$ in the second and $27.2 \%$ in the third. Among the infected patients, the crude excess mortality for patients with A. baumannii-associated infection ranged from $10.1 \%$ in the first survey to $25.7 \%$ in the second and $7.9 \%$ in the third.

\section{Discussion}

Indicators of HAls provided by surveillance activities require comparison with adequate reference data to stimulate further infection control activities. In fact, HAl indicators have been used widely as benchmarks to enhance quality of care. ${ }^{12}$ SPINUTI indicators computed for the first two surveys were similar to those described in European reports. ${ }^{13-16}$ The most recent European data reported that, of 70,648 patients staying more than two days in an ICU, 7.1\% acquired pneumonia and $4.7 \%$ acquired a BSI. ${ }^{16}$

Surveillance of HAls, in conjunction with appropriate infection control activities, have been reported by the Study of the Efficacy of Nosocomial Infection Control (SENIC) as an efficacious tool to reduce HAls. ${ }^{17}$ Other subsequent studies have reported a reduction of the HAI rates in ICU patients. ${ }^{5-7}$ Furthermore, since those studies are not controlled intervention surveys, potential bias associated with other factors, such as patient characteristics, cannot be excluded. ${ }^{7}$ Thus, it remains an open question whether the reduction in HAl rates is also influenced by confounding factors such as changes in the healthcare system, in diagnostic procedures and/or in the patient characteristics. ${ }^{3}$ However, one study reports that following implementation of an infection control programme including HAl surveillance, protocol updates in response to the data obtained, and assessment of caregiver compliance with infection control measures, there was a significant decline in the rate of urinary tract infection (UTI) and central venous catheter (CVC)-related bacteraemia but not of ventilator- 


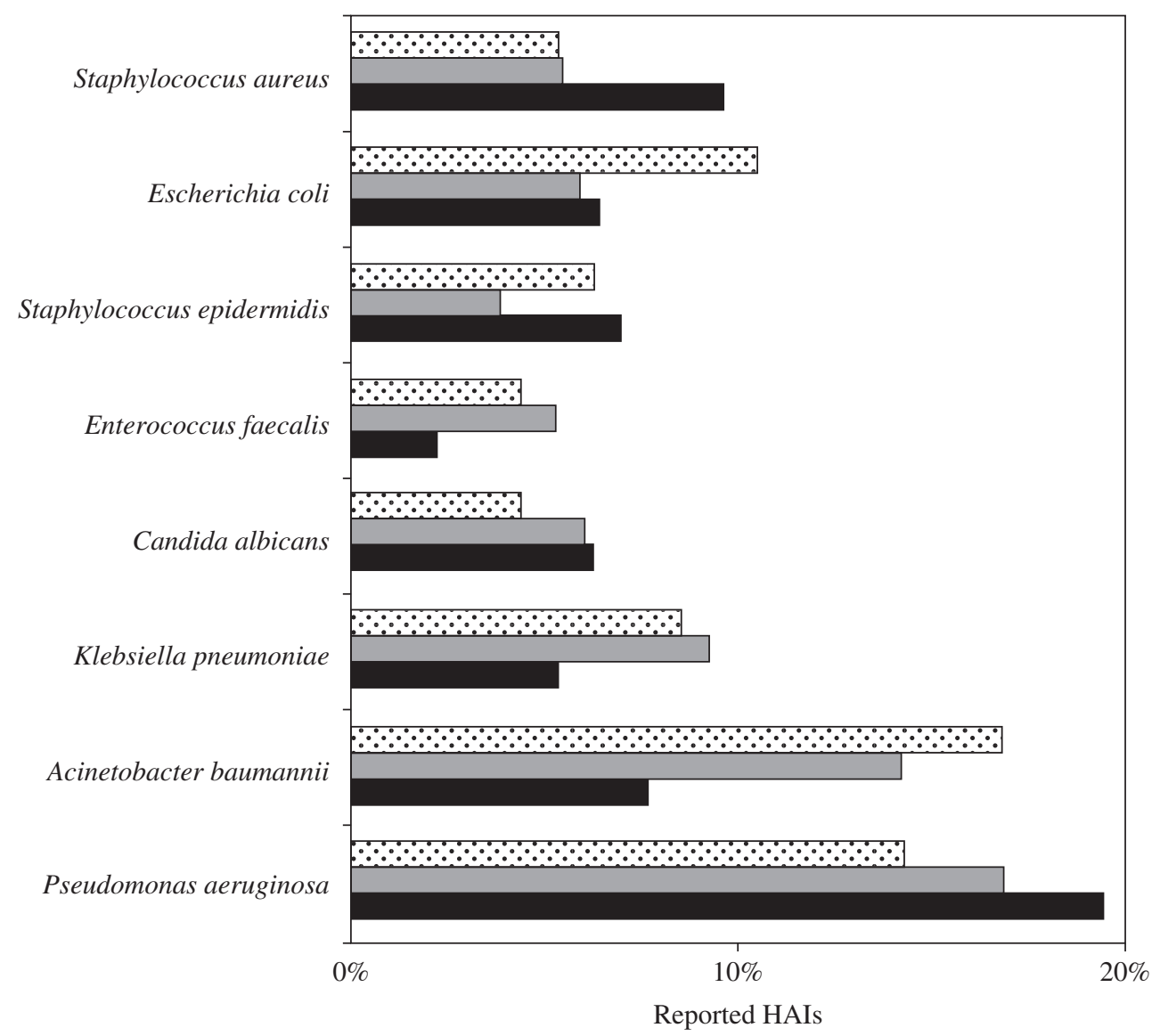

Figure 1. The most frequently reported micro-organisms in healthcare-associated infections (HAls) (per 100 micro-organisms) according to the Italian Nosocomial Infections Surveillance in Intensive Care Units (SPIN-UTI) network. Stippled bars: $2010-11$ period; grey bars: 2008-9 period; black bars: 2006-7 period.

associated pneumonia. The relatively low pneumonia rates, at programme initiation, together with the lack of effective prevention measures, was suggested to explain in part those results. $^{18}$

Participation in the SPIN-UTI surveillance was voluntary, and the number of participating hospitals and ICUs varied between surveys. A possible explanation for the decreasing number of participating ICUs observed in the last two surveys is the cost and the heavy workload required for patient-based surveillance activities. However, trends in infection rates computed for the 14 ICUs contributing data to all three surveys did not differ from those computed for all 65 ICUs included (data not shown). In order to take into account such a potential source of bias, we adjusted for patients' characteristics not only on admission, but also in terms of the length of stay in ICUs and exposure to invasive devices. In the SPIN-UTI project, riskadjusted indicators of HAls show that, despite urinary catheter-associated UTI rates and CVC-related infection rates remaining unchanged during the three surveys, both the intubator-associated pneumonia rate and BSI rate significantly increased in the third survey. The real reasons for the increase are difficult to determine. However, device-associated infection rates and device utilization ratios should be examined together, so that preventive measures may be appropriately targeted. ${ }^{19}$ In the SPIN-UTI project, an increase in the intubator-associated pneumonia rate was shown together with a decrease in the intubator utilization ratio. Therefore, because intubation is a significant risk factor for pneumonia, it is recommended to target efforts not only towards reducing the use of the device or limiting the duration of usage, but also towards the appropriate management of intubation procedures.

Furthermore, since the patient-based component of the European protocol has been adopted for the SPIN-UTI surveillance, data on risk factors and risk-adjusted indicators were used in order to investigate sources of variation. Importantly, the HAl rate increase observed in the present study was shown to be associated with disease severity and treatment intensity, as high SAPS II score and patient origin from the hospital were identified as independent risk factors, and they were shown to increase significantly in the third survey.

Finally, the first and the second surveys of the SPIN-UTI project adopted methods and definitions of the HELICS-ICU protocol, whereas in the third survey, the protocol was updated following the ECDC HAIICU protocol. In particular the SPIN-UTI protocol was updated, removing some variables such as those related to CVC risk factors and the Glasgow score. The list of micro-organisms was updated. The format of device and antibiotic exposure data, with a start date and an end date, introduced in the new European protocol have already been included in the SPIN-UTI protocol since its first edition. As such, none of the changes in the protocol is likely to affect infection rates. 
Table III

Relative frequency (\%) by site of the most numerous isolated micro-organisms in intensive care unit-acquired infection

\begin{tabular}{|c|c|c|c|}
\hline \multirow[t]{2}{*}{ Site/micro-organism } & \multicolumn{3}{|c|}{ SPIN-UTI } \\
\hline & $\begin{array}{c}2006- \\
2007\end{array}$ & $\begin{array}{r}2008- \\
2009\end{array}$ & $\begin{array}{r}2010 \\
2011\end{array}$ \\
\hline \multicolumn{4}{|l|}{ Pneumonia } \\
\hline Pseudomonas aeruginosa & $23.5 \%$ & $21.8 \%$ & $18.7 \%$ \\
\hline Staphylococcus aureus & $14.1 \%$ & $8.0 \%$ & \\
\hline Acinetobacter baumannii & $10.6 \%$ & $19.1 \%$ & $22.0 \%$ \\
\hline Escherichia coli & & & $10.1 \%$ \\
\hline \multicolumn{4}{|l|}{ Bloodstream infection } \\
\hline Staphylococcus epidermidis & $24.0 \%$ & $12.4 \%$ & $20.6 \%$ \\
\hline Pseudomonas aeruginosa & $11.1 \%$ & $11.6 \%$ & \\
\hline Candida albicans & $7.6 \%$ & & \\
\hline Acinetobacter baumannii & $11.6 \%$ & & $11.1 \%$ \\
\hline Klebsiella pneumoniae & & $11.6 \%$ & $9.4 \%$ \\
\hline \multicolumn{4}{|l|}{ Urinary tract infection } \\
\hline Pseudomonas aeruginosa & $20.7 \%$ & $14.0 \%$ & $12.5 \%$ \\
\hline Candida albicans & $18.9 \%$ & & \\
\hline Escherichia coli & $18.9 \%$ & $13.1 \%$ & $22.9 \%$ \\
\hline Acinetobacter baumannii & & & $12.5 \%$ \\
\hline Klebsiella pneumoniae & & $13.1 \%$ & \\
\hline \multicolumn{4}{|l|}{ Catheter-related infection } \\
\hline Pseudomonas aeruginosa & $11.9 \%$ & & $18.8 \%$ \\
\hline Staphylococcus epidermidis & $11.9 \%$ & $10.0 \%$ & \\
\hline Staphylococcus haemolyticus & $11.9 \%$ & & \\
\hline Acinetobacter baumannii & $9.5 \%$ & $15.0 \%$ & $12.5 \%$ \\
\hline Klebsiella pneumoniae & $9.5 \%$ & $10.0 \%$ & $12.5 \%$ \\
\hline Staphylococcus: other spp. & & $12.5 \%$ & \\
\hline
\end{tabular}

SPIN-UTI, Italian Nosocomial Infections Surveillance in Intensive Care Units network.

The pattern of distribution of the major micro-organisms isolated in the Italian ICUs underlines the importance of some pathogens common to all European countries, and the emergence of specific pathogens such as $A$. baumannii in countries such as Italy, Lithuania, Portugal, Slovakia and Spain..$^{8,13,16,20}$ The present study also showed the increasing impact of $A$. baumannii, ranking the most frequently reported micro-organism in the third survey. However, this feature cannot be considered an explanatory factor as risk trends estimated by computing indicators for A. baumannii-associated infections did not differ significantly from those computed for other micro-organisms.

A most important part of hospital epidemiology is to study the impact of risk factors on clinical outcomes and ICU mortality. Although in our study mortality rates remained unchanged, the risk of death significantly increased among infected patients. Overall estimates highlight that HAls treble the risk of death, with an increasing crude excess mortality for patients with pneumonia during the three surveys, an increasing crude excess mortality for patients with BSI in the first and second surveys, and an additional effect of $A$. baumannii-associated infections in the first and second surveys.

The answer of the international scientific community to the growing challenge represented by the HAI risk in ICU patients consists mainly of efforts to implement and fulfill multidisciplinary projects. In the European context, the IMPLEMENT project was designed to spread and test knowledge on how to implement strategic bundles for infection prevention and management in a sample of European ICUs, in order to investigate the effectiveness of tailored strategies to implement bundled evidence-based preventive interventions on a large scale (http://www.eu-implement.info). In fact, identification of the most successful implementation tools for bundled interventions will provide important information for policymakers, managers, and healthcare workers on best practices for tackling the HAl problem. ${ }^{21}$

In conclusion, our study highlighted the increased risk of $\mathrm{HAI}$, at least partially explained by the greater severity and number of hospitalized patients requiring ICU admission. Our patientbased cohort design allowed us to compute detailed estimates of the outcomes of infections such as case fatality rate and the emerging role of $A$. baumannii in the Italian ICUs. We identified the management of intubation procedures and of ventilated patients as a potential target for infection control interventions and as such the need of implementation of strategic bundles in order to decrease the growing risk of HAI in the ICUs.

\section{Acknowledgements}

The authors wish to thank all colleagues from the ECDC for their close co-operation during the development of this surveillance study, and all physicians and nurses in the participating hospitals for providing surveillance data: Centro di Ricerche e Formazione ad Alta Tecnologia nelle Scienze Biomediche - Giovanni Paolo II - Università Cattolica Del Sacro Cuore, Campobasso; Ospedale 'Luigi Sacco', Milano; AOU 'G. Martino', Messina; AOUP 'Paolo Giaccone' di Palermo; ASL n 1 Sassari; ASL Roma $\mathrm{H}$ Polo H 4 P.O. Anzio; ASP di Caltanissetta Presidio Ospedaliero Sant'Elia di Caltanissetta; ASP di Palermo; AUSL 7 Ragusa Ospedale Maggiore di Modica; AUSL n ${ }^{\circ} 4$ Lanusei - P.O. 'Nostra Signora della Mercede'; Azienda Ospedaliera 'Istituti Ospitalieri', Cremona - Presidio Ospedaliero di Oglio Po; Azienda Ospedaliera 'Istituti Ospitalieri', Cremona; Azienda Ospedaliera 'Cannizzaro', Catania; Azienda Ospedaliera 'Pugliese-Ciaccio', Catanzaro; Azienda Ospedaliera ARNAS 'Civico-Ascoli-Di Cristina' Palermo; Azienda Ospedaliera di Cosenza; Azienda Ospedaliera di Melegnano - Presidio Ospedaliero di Cernusco sul Naviglio; Azienda Ospedaliera Ospedale Niguarda Ca' Granda di Milano; Azienda Ospedaliero - Universitaria Policlinico di Bari, Regione Puglia; Azienda Ospedaliera S. Giovanni di Dio, Agrigento; Azienda Ospedaliera Universitaria di Parma; Azienda Ospedaliera Universitaria di Udine; Azienda Ospedaliero Universitaria Policlinico di Modena; Azienda Ospedaliero - Universitaria 'Policlinico - Vittorio Emanuele', Catania; Azienda Ospedaliero Universitaria di Verona; Azienda ULSS 18 di Rovigo; Azienda ULSS 20 di Verona - Ospedale di San Bonifacio; Azienda ULSS 21 di Legnago; Azienda USL 9 di Trapani - Presidio Ospedaliero 'Vittorio Emanuele II $^{\circ}$ ' di Castelvetrano; DEU (Dipartimento Emergenza Urgenza), Palermo; Fondazione IRCCS Ca' Granda Ospedale Maggiore Policlinico, Milano; IRCCS Fondazione Salvatore Maugeri, Istituto Scientifico di Pavia; IRCCS Fondazione Salvatore Maugeri, Istituto Scientifico di Riabilitazione di Veruno; IRCCS Istituto Clinico Humanitas, Milano; IRCCS Ospedale San Raffaele, Milano; ISCAS Morgagni Nord srl di Pedara; Istituto Clinico S. Anna, Brescia; Istituto Clinico S. Rocco, Ome; Ospedale Buccheri - La Ferla di Palermo; Presidio Ospedaliero S. Salvatore, L'Aquila; Presidio Ospedaliero 'Guzzardi' di Vittoria; Presidio Ospedaliero SS. Annunziata, Taranto; USL n`3 Nuoro; Villa Sofia, Palermo. 
Conflict of interest statement

None declared.

\section{Funding sources}

None.

\section{References}

1. Geubbels EL, Nagelkerke NJ, Mintjes-De Groot AJ, et al. Reduced risk of surgical site infections through surveillance in a network. Int J Qual Health Care 2006;18:127-133.

2. Rioux C, Grandbastien B, Astagneau P. Impact of a six-year control programme on surgical site infections in France: results of the INCISO surveillance. J Hosp Infect 2007;66:217-223.

3. Gastmeier P, Schwab F, Sohr D, Behnke M, Geffers C. Reproducibility of the surveillance effect to decrease nosocomial infection rates. Infect Control Hosp Epidemiol 2009;30: 993-999.

4. Geffers C, Gastmeier P. Nosocomial infections and multidrug resistant organisms in Germany - epidemiological data from KISS (The Hospital Infection Surveillance System). Dtsch Arztebl Int 2011;108:87-93.

5. Zuschneid I, Schwab F, Geffers C, Ruden H, Gastmeier P. Reducing central venous catheter-associated primary bloodstream infections in intensive care units is possible: data from the German nosocomial infection surveillance system. Infect Control Hosp Epidemiol 2003;24:501-505.

6. Gastmeier P, Geffers C, Brandt C, et al. Effectiveness of a nationwide nosocomial infection surveillance system for reducing nosocomial infections. J Hosp Infect 2006;64:16-22.

7. Zuschneid I, Schwab F, Geffers C, Behnke M, Ruden H, Gastmeier P. Trends in ventilator-associated pneumonia rates within the German Nosocomial Infection Surveillance System (KISS). Infect Control Hosp Epidemiol 2007;28:314-318.

8. Agodi A, Auxilia F, Barchitta M, et al. Building a benchmark through active surveillance of ICU-acquired infections: the Italian network SPIN-UTI. J Hosp Infect 2010;74:258-265.

9. HELICS-ICU Working Group. Surveillance of nosocomial infections in intensive care units. Protocol, version 6.1. IPH/EPI reports D/2004/2505/48. Brussels: Scientific Institute of Public Health; 2004.

10. European Centre for Disease Prevention and Control. European surveillance of healthcare-associated infections in intensive care units. ECDC HAlICU protocol V1.01 Standard and Light. Stockholm: ECDC; 2010.

11. Masia MD, Barchitta M, Liperi G, et al. Validation of intensive care unit-acquired infection surveillance in the Italian SPIN-UTI network. J Hosp Infect 2010;76:139-142.

12. Haustein $T$, Gastmeier P, Holmes A, et al. Use of benchmarking and public reporting for infection control in four high-income countries. Lancet Infect Dis 2011;11:471-481.

13. Lambert ML, Suetens C, Savey A, et al. Clinical outcomes of health-care-associated infections and antimicrobial resistance in patients admitted to European intensive-care units: a cohort study. Lancet Infect Dis 2011;11:30-38.

14. European Centre for Disease Prevention and Control. Annual epidemiological report on communicable diseases in Europe 2009. Stockholm: ECDC; 2009.

15. European Centre for Disease Prevention and Control. Annual epidemiological report on communicable diseases in Europe 2010. Stockholm: ECDC; 2010.

16. European Centre for Disease Prevention and Control. Annual epidemiological report 2011. Reporting on 2009 surveillance data and 2010 epidemic intelligence data. Stockholm: ECDC; 2011.

17. Haley RW, Culver DH, White JW, et al. The efficacy of infection control programs in preventing nosocomial infections in U.S. hospitals. Am J Epidemiol 1985;212:182-205.

18. Misset B, Timsit JF, Dumay MF, et al. A continuous qualityimprovement program reduces nosocomial infection rates in the ICU. Intensive Care Med 2004;30:395-400.

19. Edwards JR, Peterson KD, Mu Y, et al. National Healthcare Safety Network (NHSN) report: data summary for 2006 through 2008, issued December 2009. Am J Infect Control 2009;37:783-805.

20. Agodi A, Voulgari E, Barchitta M, et al. Containment of an outbreak of KPC-3 carbapenemase-producing Klebsiella pneumoniae in Italy. J Clin Microbiol 2011;49:3986-3989.

21. Kaier $\mathrm{K}$, Wilson $\mathrm{C}$, Hulscher $M$, et al. Implementing strategic bundles for infection prevention and management. Infection 2012;40:225-228. 